\title{
ANM 2016 \\ Influence of operating parameters and ion doping on the photocatalytic activity of mortars containing titanium dioxide nanoparticles
}

\author{
S. S. Lucas ${ }^{\mathrm{a}, \mathrm{b} *}$ \\ ${ }^{a}$ Faculty of Engineering and Science, Department of Engineering Science, University of Greenwich, United Kingdom \\ ${ }^{b}$ CICECO/Department of civil engineering, University of Aveiro, Portugal
}

\begin{abstract}
Photocatalytic materials are considered an effective solution to improve air quality in urban areas and have been extensively studied in the past decade. The use of nanoparticles as photocatalyzers proved very effective however, the operational conditions can determine how successful the solution will be. For mortars containing nanoparticle of titanium dioxide, the photocatalytic degradation of air pollutants can be compromised by surface contamination, the pollutant's concentration, and the deactivation time. In this work, the influence of these operational parameters has been studied alongside with a method to improve the photocatalytic activity by using $\mathrm{Fe}^{3+}$ ion doping.
\end{abstract}

Keywords: Titanium dioxide; ion doping; photocatalysis; mortars; self-cleaning; NOx

\section{Main text}

In the study of self-cleaning materials for construction, titanium dioxide nanoparticles have been amongst the most studied. Its incorporation in building materials has shown promising results for self-cleaning and depolluting applications. Indoor air quality in buildings is now going far beyond the simple indoor temperature regulation. Other aspects like contamination of the indoor air by pollutants, are gaining importance and researchers are trying to develop

\footnotetext{
* Corresponding author. Tel.: +44-(0)1634883019.

E-mail address: sandra@sandralucas.pt
} 
methods to mitigate the impact of such pollutants, to reduce adverse effects on human health [1]. Internal sources wall paints, materials and coatings (applied in furniture), tobacco smoke, fireplaces and stoves are usually the main cause of contamination consequently, different types of contaminants (VOC, NOx, SOx, formaldehyde, etc.) can be present inside the buildings, sometimes in higher concentrations than outside. Titanium dioxide $\left(\mathrm{TiO}_{2}\right)$ is effective for removal of several air pollutants, presenting itself as a suitable solution for indoor air cleaning. Although the photocatalytic activity is quite high, even with levels of incorporation as low as $5 \%$, the use of nanoparticles in mortars is complex. Adding nano-TiO2 to mortars causes important changes on the microstructural level and their understanding is fundamental to achieve successful applications [2]. The photocatalytic efficiency is dependent on external factors like humidity and pollutant concentration. Modification of the photocatalytic additive by ion doping can also be used to increase performance. To reduce the content of photocatalytic additive and maintain the same level of efficiency, ways of increasing $\mathrm{TiO}_{2}$ catalytic activity and the impact of the external factors have been studied.

\subsection{Experimental/theoretical study}

Commercial titanium dioxide nanoparticles were mixed with cement and lime-based mortars. The influence of different operating parameters in the photocatalytic activity has been studied. Factors such as the deactivation time, the initial pollutant concentration and the effect of metal doping, have been investigated. Titanium dioxide nanoparticles were doped with iron ions $\left(\mathrm{Fe}^{3+}\right)$ by co-precipitation. The efficiency of these mortars to degrade NOx was studied and compared with samples with non-doped titanium dioxide.

\subsubsection{Photocatalytic degradation of indoor pollutants}

Photocatalytic effect has been well known for many decades. Two different catalyzers are amongst the most investigated, zinc oxide ( $\mathrm{ZnO}$ ) and titanium dioxide ( $\mathrm{TiO} 2)$ [3, 4]. Applications with titanium dioxide have been done with two different crystalline phases: rutile and anatase with $\mathrm{TiO} 2$ being by far, the most studied. The anatase form, due to its high chemical stability, good efficiency and relative low cost is preferred, when compared with other catalysts [5]. Production of $\mathrm{TiO}_{2}$ in nano-sized particles contributed to greatly improve the photocatalytic efficiency, a result of its higher surface area that resulted in higher reactivity. Titanium dioxide reacts with some common pollutants like VOC, NOx and Sox and is able to degrade them, transforming these harmful substances into safe reaction products that can be easily removed [6-8].

Being one of the most common pollutants present in indoor air nitrogen oxides (NOx), are amongst the preferred contaminants for assessing photocatalytic efficiency in construction materials. Equations 1 to 3 describe the degradation process, where $\mathrm{OH}$ and $\mathrm{O}_{2}^{-}$radicals created during the photocatalytic activation reacts with $\mathrm{NO} 2$ to produce HNO3 [9].

$$
\begin{aligned}
& \mathrm{NO}+\mathrm{OH}^{-} \rightarrow \mathrm{NO}_{2}+\mathrm{H}^{+} \\
& \mathrm{NO}_{2}+\mathrm{OH}^{-} \rightarrow \mathrm{HNO}_{3} \\
& \mathrm{NO}+\mathrm{O}_{2}^{-}+\rightarrow \mathrm{NO}_{3}^{-}
\end{aligned}
$$

The use of wall coatings (mortars or paints) with the capability to degrade pollutants increases durability and improves indoor air quality.

\subsubsection{Photocatalytic tests}

To conduct the photocatalytic test, a specific setup using NOx as a pollutant was developed. NOx is a common pollutant gas present inside buildings and urban areas, in concentrations around $1 \mathrm{ppmv}$. This value was selected as the initial concentration for the laboratory tests conducted in this study. NOx (10 ppmv) was diluted in standardized air, to obtain the desired concentration. Gas inlet measured with mass flow controllers was injected to the chamber at a constant flow rate of $1 \mathrm{l} / \mathrm{min}$. The reaction took place inside the stainless steel chamber. The cylinder with a $35 \mathrm{~L}$ capacity is completely sealed and the glass window on the top allowed the light from the 300-Watt solar lamp (OSRAM UltraVitalux), placed at $1 \mathrm{~m}$ from the sample, to irradiate the mortar [10]. During the tests, a thermocouple 
and a humidity sensor monitored temperature and humidity, and the values remained steady at $200 \mathrm{C}$ and $40 \%$ respectively. Excessive temperature can affect the photocatalytic measurements making difficult to distinguish the degradation effect from an overheating phenomenon. A chemiluminescence analyzer (AC-30 M, Environment SA) measured the concentration of the outlet gas [6].

The photocatalytic efficiency is determined by equation 5 , where $[\mathrm{NOx}]_{\mathrm{TiO} 2}$ is the final pollutant concentration after the irradiation test and $[\mathrm{NOx}]_{\text {blank }}$ is the NOx concentration for the blank test $\left(0 \% \mathrm{TiO}_{2}\right)$.

$$
\mathrm{NOX}_{\text {removed }}=\frac{[\mathrm{NOx}]_{\mathrm{TiO}_{2}}-[\mathrm{NOx}]_{\text {blank }}}{\left[\mathrm{NOx}_{\mathrm{TiO}_{2}}\right.} \times 100
$$

Some operational aspects, such as the deactivation time and initial pollutant concentration can influence the degradation efficiency [11]. It is important to verify if the samples confinement in a place with absence of light for a period of several hours is enough to assure the complete deactivation of the catalyzer, allowing the mortar to perform a new photocatalytic cycle when exposed to the sunlight again. This is a fundamental evaluation to determine if the mortar maintains its efficiency when subjected to several activation and deactivation series throughout its life cycle. For this purpose, a 2-cycle test was performed, with an 8 hours deactivation interval in a dark box.

To assess the influence of the pollutant concentration on the photocatalytic degradation rate a mortar sample, selected from the compositions previously tested, was submitted to cycles with concentrations of $0.5 \mathrm{ppmv}$ and 0.75 ppmv. The composition was selected based on the hardened state performance and the photocatalytic degradation efficiency. Considering these results and taking into account that the mortars with lime, less studied, are particularly interesting for application in the rehabilitation of old buildings, was selected the lime-gypsum composition (LG). Several authors have tested different doping methods trying to increase the efficiency of the catalyst. These methods involve doping titanium dioxide with metals (e.g., silver or iron) [12, 13]. In this work, a co-precipitation method was used for doping the titanium dioxide with iron $\left(\mathrm{Fe}^{3+}\right)[14]$. The samples were prepared with $1 \mathrm{wt} \%$ nano-TiO $\mathrm{T}_{2}$ doped with iron for tests in the photocatalytic reactor and compared with the same mortar composition prepared with the non-doped $\mathrm{TiO}_{2}$.

\subsection{Results and discussion}
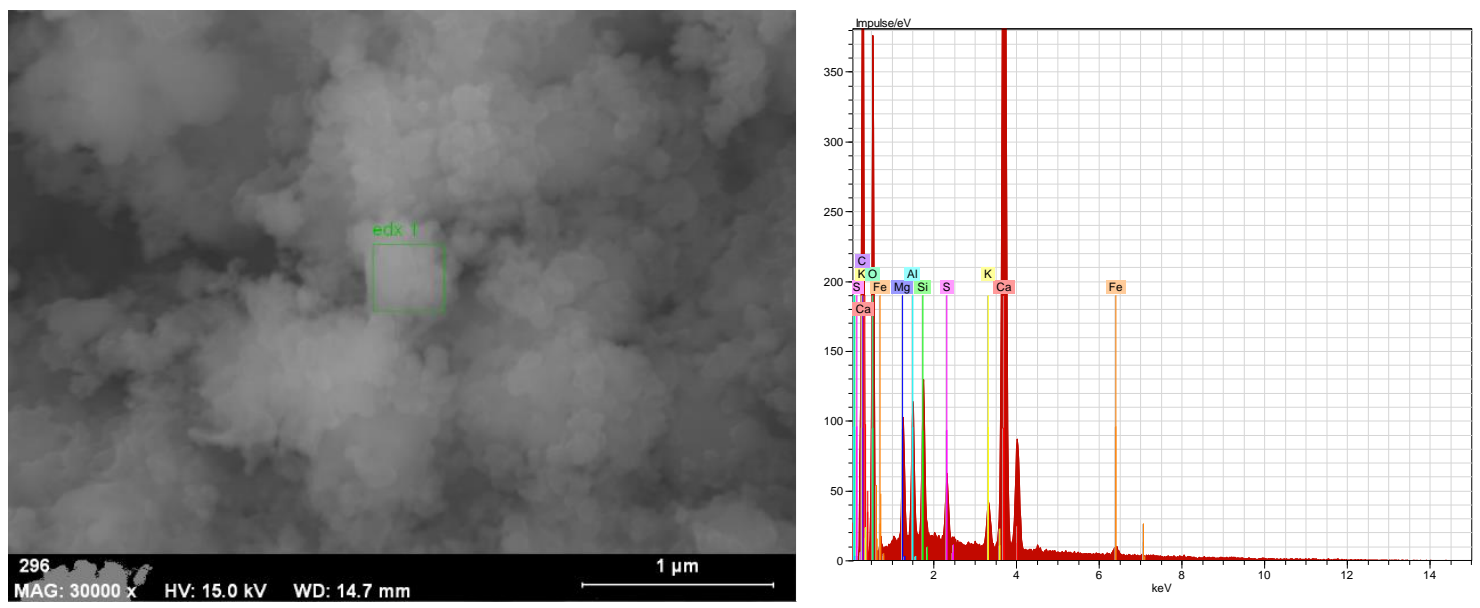

Fig. 1 Iron-doped titanium dioxide SEM and EDX analysis

The analysis of the titanium dioxide powder showed that the co-precipitation method was effective (Figure 1), as the EDX analysis clearly shows. The samples, prepared with $1 \%$ of iron-doped $\mathrm{TiO}_{2}$, were tested in the photocatalytic reactor and the overall efficiency of the ion-doped samples is almost $10 \%$ higher than the non-doped (Figure2). 
Although this is not a massive increment, it leaves room for reducing the amount of catalyst in the mortar maintaining the efficiency, reducing the product's final cost. Ion doping should therefore be considered as a suitable alternative to increase photocatalytic activity.

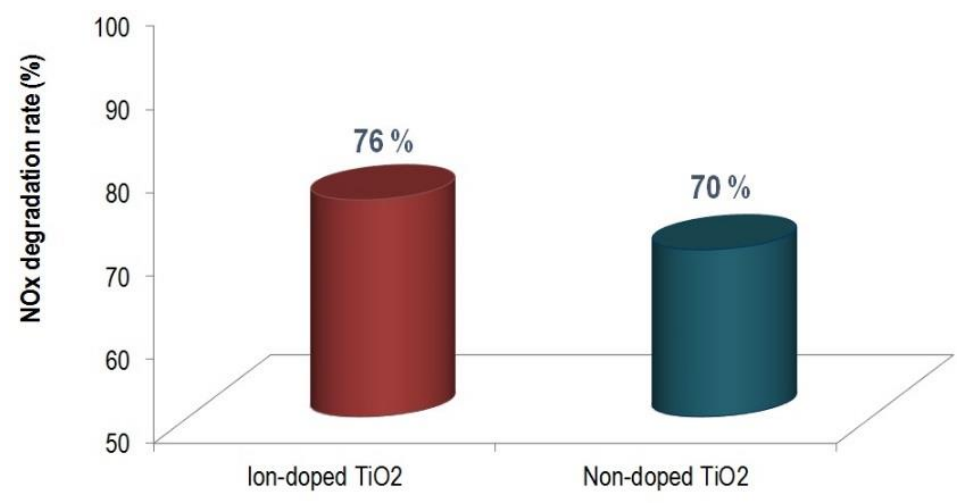

Fig. 2 Photocatalytic efficiency for the iron-doped titanium dioxide

The mortar's surface can undergo temporary deactivation when reaction products are deposited on the active sites of the catalyst, a critical aspect that can limit or restrict the functional application of the phototocatalyst [15]. Deactivation can be reversible or irreversible, depending on the nature of the catalyst and the type of reaction products. During the pollutant's degradation process, some intermediate products are formed and, because they have a higher adsorption rate, they deposit on the surface and block the pollutant's access to $\mathrm{TiO}_{2}$.

The contamination effect was observed in this work when the samples were tested in different sets of three consecutive tests. Under the same conditions of concentration, temperature and humidity, they exhibited a consistent decrease in the photocatalytic efficiency, as seen in Figure 3.
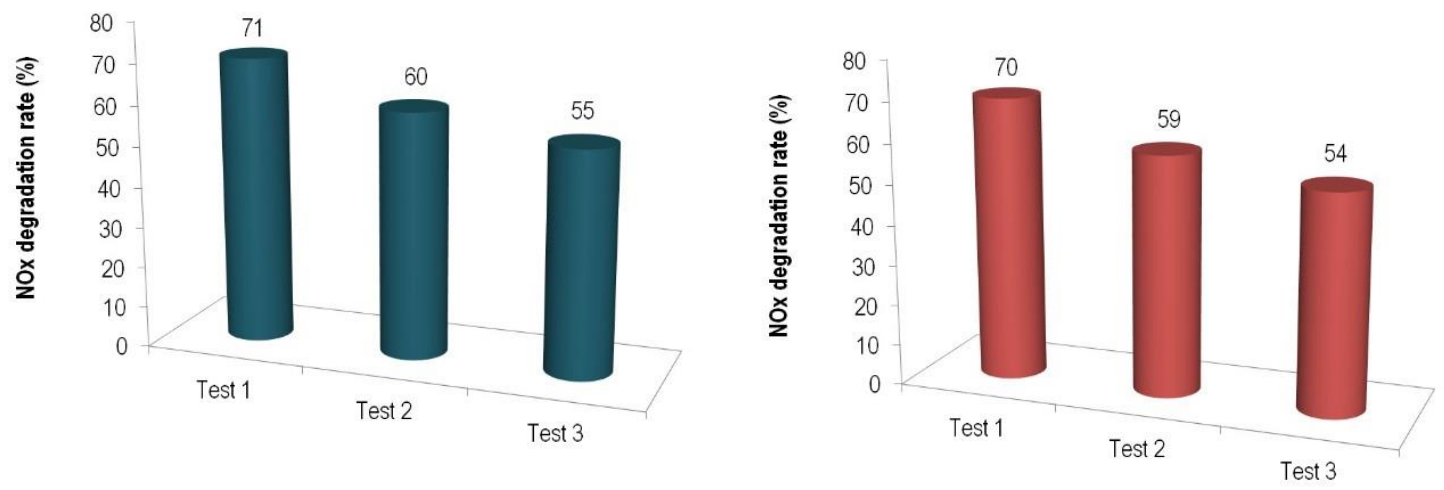

Fig. 3 Contamination effect on photocatalysis

According to Cao et al. study, it was proven that this effect is usually reversible and the catalytic activity can be completely restored after a period of inactivation [16]. The materials developed in this study are to be applied as inner wall coatings so, it is expected an 8-hour period with absence of sunlight each day. Theoretically, this should suffice to deactivate the surface however, a laboratory test needed to be conducted to confirm this. The samples were subjected to the photocatalytic degradation test and they were stored in a dark box for $8 \mathrm{~h}$, immediately after. After the 8 hours, the photocatalytic test was repeated under the same conditions and the results are presented in Figure 3 . The 
deactivation proved to be effective and it has been demonstrated that absence of light is enough to ensure an effective removal of the reaction products. All active sites on the mortar's surface will be available again for a new photocatalytic cycle.

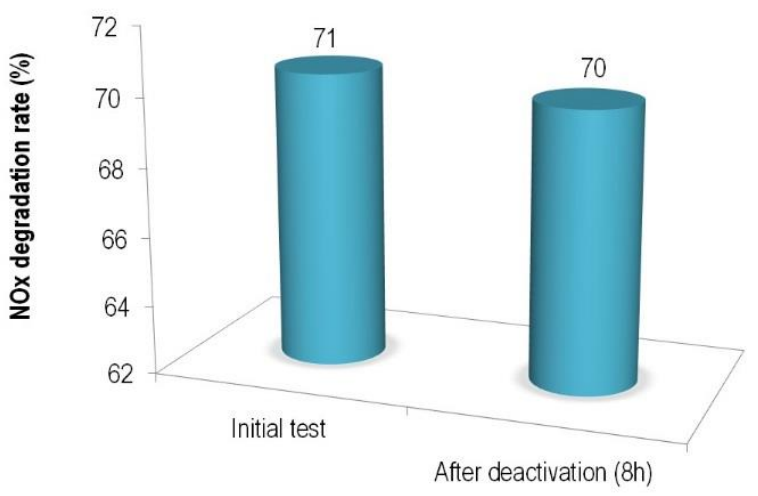

Fig. 4 Photocatalytic efficiency before and after deactivation

The influence of the pollutant's concentration is almost as relevant as deactivation and is known to affect the photocatalytic efficiency [17]. To evaluate photocatalysis for [NOx] concentrations below $1 \mathrm{ppmv}$, the mortars were tested with 0.7 and $0.5 \mathrm{ppmv}$ (Figure 4). Taking for reference other published results, an increase in efficiency was expected and confirmed; reducing [NOx] to $0.7 \mathrm{ppmv}$ and $0.5 \mathrm{ppmv}$ increased the efficiency by $9 \% 12 \%$ respectively. This increment is not directly proportional to the reduction in concentration, though; it is not expected to reach 100 $\%$. To understand the loss of efficiency with higher concentrations, it is necessary to understand the reaction mechanism for NOx degradation. This is a two-stage process where the electron-hole pairs are created and afterwards, the reaction with the pollutant takes place. The efficiency is higher with lower concentrations of NOx because not all the active sites are required for the initial stage of the catalysis, when the first intermediate products are formed. With higher NOx concentrations, there is an extensive occupation of active sites in this first stage, due to a higher amount of intermediate products, leaving less catalyzer available for the subsequent reaction steps. Higher concentrations of pollutant lead to higher amounts of intermediate products, which reduce the degradation rate, causing a decrease in efficiency [17].

\subsection{Conclusion}

In this work it has been investigated the influence of some operational parameters in the photocatalytic efficiency of titanium dioxide nanoparticles $\left(\mathrm{TiO}_{2}\right)$. It was also studied the effect of iron doping in photocatalysis and was demonstrated that the efficiency improved without the need of a higher content of nanoparticles.

It has been concluded that:

- When the sample is placed on a site without access to sunlight for 8 hours, the catalyst deactivates maintaining the photocatalytic efficiency in the subsequent cycles. The reaction products, absorbed at the surface during the photocatalysis, are completely removed. The deactivation test indicates that when the mortar is used in building walls maintain its photocatalytic efficiency.

- The reduction of the pollutant initial concentration increases the degradation rate. A lower NOx concentration reduces the number of catalyst active sites needed to degrade the pollutant, increasing the reaction speed. For higher concentrations, the demand of active sites for the degradation process and larger quantities of intermediate products slow down the degradation rate.

- It was shown that doping titanium dioxide nanoparticles with iron (by a co-precipitation method) improves the photocatalytic efficiency leaving room to reduce the amount of nanoparticles added to the mortar. 


\section{References}

1. L. Zhong, F. Haghighat, P. Blondeau, J. Kozinski, Modeling and physical interpretation of photocatalytic oxidation efficiency in indoor air applications, Building and Environment 45(12) (2010) 2689-2697.

2. S.S. Lucas, V.M. Ferreira, J.L.B.d. Aguiar, Incorporation of titanium dioxide nanoparticles in mortars — Influence of microstructure in the hardened state properties and photocatalytic activity, Cement and Concrete Research 43 (2013) 112-120.

3. P. Sikora, E. Horszczaruk, T. Rucinska, The Effect of Nanosilica and Titanium Dioxide on the Mechanical and Self-Cleaning Properties of Waste-Glass Cement Mortar, Procedia Engineering 108 (2015) 146-153.

4. C.H. Ma, L.Q. Zhang, H.B. Zhang, J. Wang, Degradation of organic pollutants by air bubbles passing small glass balls in the presence of nanosized ZnO powder, Russian Journal of Physical Chemistry A 89(10) (2015) 1884-1890.

5. S.W. Verbruggen, T. Tytgat, S. Van Passel, J.A. Martens, S. Lenaerts, Cost-effectiveness analysis to assess commercial TiO2 photocatalysts for acetaldehyde degradation in air, Chemical Papers 68(9) (2014) 1273-1278.

6. A. Mills, S. Elouali, The nitric oxide ISO photocatalytic reactor system: Measurement of NOx removal activity and capacity, Journal of Photochemistry and Photobiology A: Chemistry 305 (2015) 29-36.

7. D.J. Kim, A. Nasonova, J.H. Park, J.Y. Kang, K.S. Kim, NOx and SOx removal by low temperature plasma-photocatalysts hybrid system, Materials science forum, Trans Tech Publ, 2007, pp. 91-94.

8. J.H. Mo, Y.P. Zhang, Q.J. Xu, J.J. Lamson, R.Y. Zhao, Photocatalytic purification of volatile organic compounds in indoor air: A literature review, Atmospheric Environment 43(14) (2009) 2229-2246.

9. K. Skalska, J.S. Miller, S. Ledakowicz, Trends in NOx abatement: A review, Science of The Total Environment 408(19) (2010) $3976-3989$.

10. A. Pal, S.O. Pehkonen, L.E. Yu, M.B. Ray, Photocatalytic Inactivation of Airborne Bacteria in a Continuous-Flow Reactor, Industrial \& Engineering Chemistry Research 47(20) (2008) 7580-7585.

11. M. Hunger, G. Husken, J. Brouwers, Photocatalysis applied to concrete products - Part 2 : Influencing factors and product performance, $Z k g$ International 61(10) (2008) 76-84.

12. K. KocÌ, K. Mateju, L. Obalov·, S. Krejcl̀kov•, Z. Lacn", D. Plach·, L. Capek, A. Hospodkov•, O. Solcov·, Effect of silver doping on the $\mathrm{TiO} 2$ for photocatalytic reduction of CO2, Applied Catalysis B: Environmental 96(3-4) (2010) 239-244.

13. H.W. Shi, J.T. Zheng, Y. Hu, Y.C. Zhao, Influence of Fe3+ and Ho3+ co-doping on the photocatalytic activity of TiO2, Materials Chemistry and Physics 106(2-3) (2007) 247-249.

14. I. Ganesh, P.P. Kumar, A.K. Gupta, P.S. Sekhar, K. Radha, G. Padmanabham, G. Sundararajan, Preparation and characterization of Fe-doped $\mathrm{TiO} 2$ powders for solar light response and photocatalytic applications, Processing and application of ceramics 6(1) (2012) 21-36.

15. A. Fujishima, X.T. Zhang, D.A. Tryk, TiO2 photocatalysis and related surface phenomena, Surface Science Reports 63(12) (2008) 515-582.

16. L. Cao, Z. Gao, S.L. Suib, T.N. Obee, S.O. Hay, J.D. Freihaut, Photocatalytic Oxidation of Toluene on Nanoscale TiO2 Catalysts: Studies of Deactivation and Regeneration, Journal of Catalysis 196(2) (2000) 253-261.

17. O. Carp, C.L. Huisman, A. Reller, Photoinduced reactivity of titanium dioxide, Progress in Solid State Chemistry 32(1-2) (2004) 33-177. 